\title{
Exploring the service-oriented enterprise: Drawing lessons from a case study
}

\author{
Marijn Janssen \\ School of Technology, Policy and Management, \\ Delft University of Technology, \\ Jaffalaan 5, NL-2600 GA, Delft, The Netherlands, \\ Tel. +31 (15) 2781140 , Fax. +31152783741 , \\ E-mail:m.f.w.h.a.janssen@tudelft.nl
}

\begin{abstract}
The service-oriented enterprise (SOE) is often considered as the future model of organization. Yet there is little empirical research in this domain and limited insight into the benefits and disadvantages. In this paper we analyze a case study of a large, multinational banking company. This company is modularized in functions and business domains and organized around service centers.

We found that the SOE emerges and evolves from the implementation of new projects. New banking products and services can be created by deploying service centers. Our finding shows that a serviceoriented structure has advantages concerning the timeto-market of products, reduction of duplicate activities and systems, and clarity of the governance structure. Nevertheless many of the expected benefits are not proven the SOE has a number of disadvantages that need to be dealt with.
\end{abstract}

\section{Introduction}

This idea of the Service-Oriented Enterprise (SOE) originates from the introduction of service-oriented architectures (SOAs), in which an application is constructed from well-defined and readily available components [1]. Service-oriented architectures are becoming the prominent paradigm for building enterprise information systems [2]. To date, the majority of the focus on SOA and web service has been on technical details of defining interfaces [3].

The service-oriented architecture (SOA) enables the introduction of the SOE [4] and "the parallel evolutions of business and IT raise the new challenge of establishing a tighter linkage between business strategy and IT" [5, p. 666]. A SOA is essentially an architecture that describes the interactions between services communicating with each other, with functions and with their operations [6]. "The serviceorientation vision offers many benefits to enterprises, and the creation of a class of enterprise services allows us to create services that are modular, accessible, welldescribed, implementation-independent and interoperable" $[1$, p. 80$]$. In this perspective managers can create new business processes based on the available business or IT-functions [7]. This should help to reduce development times, lower the time-to-market and reduce the development costs of new applications [7].

The SOE can be viewed as a set of capabilities that can be reconfigured to meet changing objectives [5]. The SOE approach moves organizations from application development to focus on the assembly of components and the coordination of those components. Cherokov [5, p. 654] argues "that the SOE involves business challenges that are more difficult to overcome than technological challenges associated with implementing an SOA infrastructure". The SOE has tremendous potential and can offer all kind of benefits as SOE can improve efficiency, reduce cost and risk, create agility and flexibility, enable reuse [6]. While conceptually appealing, there are only few reports of case studies, implementation and analyses of practices. Furthermore, implementation might be dependent on the enterprise and domain under study. Therefore we will explore a SOE in practice by conducting a case study of a company in the financial sector. Our analysis concentrates on the modularization of the business and the benefits and disadvantages of the SOE.

In the Dutch Insurance and Banking industry one third of the companies are already using SOAs [8]. $60 \%$ of the managers are aware of opportunities of SOAs, only $11 \%$ do not think that SOA provides any opportunity. Within this sector a number of large companies are frontrunners in the use of SOA, as some of the organizations have re-organized their organizational structure using service centers. Service centers are semi-autonomous business units who provide well-defined services to other business units 
based on pre-defined service level agreements $[9,10]$. The services provided by the service centers are loosely coupled and can be used to flexibly create dynamic business processes. In this paper we analyze one of the banking companies that is organized around service centers. The structure of this company is thus inspired by moving towards service-orientation. Componentization of the business and the subsequent integration into business processes can be viewed as a SOE $[4,5]$.

The structure of the paper is as follows. In the following section we discuss the background of the SOE and modularization concepts. In the section thereafter we discuss the research methodology followed by a description of a case study of the service-oriented enterprise. In section five, we discuss our findings. Finally, in section six conclusions and recommendations are drawn.

\section{Background}

\subsection{The Service-Oriented Enterprise}

The idea of SOA is to create a world of services being loosely coupled which can be flexibly combined to create dynamic business processes, new applications. This should enable the quick adaptation to changing circumstances [6]. This puts high requirements on the components used, as it requires a set of services that are reusable and can meet a variety of changing circumstances. The technological benefits of SOAs include the decoupling of service interfaces from implementation, platform independency, the support for dynamic service binding, and crosslanguage and cross-platform interoperability [1]. There is a development from the 'described, publish, interact' capability, to transforming service to enable reuse [11, 12].

The basis premise for the SOE seems to be that services, once developed, can be used for other purposes with relatively few efforts. This should lead to organizational benefits like decreasing costs, agility, flexibility and increasing service levels. Whereas SOA concerns mainly the technological part, the introduction of a SOE affects the whole organization and should be viewed is a critical decision on a strategic level that cannot be easily undone. After all, changing an organization is not easy, as it consumes a lot of resources and requires commitment at all levels in the organization.

The introduction of a SOE is an organizational design problem. Organizations consume resources for performing their activities. The limited resources and the corresponding problems form the core of organizational design [13]. Activities are commonly divided into tasks allocated to different persons or departments, as the resources of one person, department or organization are limited. The division of the activities into tasks creates a need for the coordination of these tasks.

Once organizational tasks are determined, these tasks can be viewed as modular components which in turn need to be integrated. The process of organizational decomposition and integration is realized by considering each modular component as a service, describing the service interfaces and integrating these services.

Once the modular components are identified there is a need for new business functions that concentrate on performing mere business process management and orchestration activities to enable the integration of modular components [7]. Cox and Kreger [14, p. 709] found that this new aspect includes "developing and testing applications composed of operational services, deploying and provisioning distributed service-based applications across organizational boundaries in a secure, reliable, and repeatable manner, and tracking the business impact of services on the business processes that those services support". The SOE can be viewed as an organizational arrangement consisting of service requesters and providers. The overall efforts and management attention will emphasis managing the interfaces and dependencies among services.

\subsection{Modularization}

In the SOE approach a company is considered as a collection of components that need to be integrated to fulfill a certain business need. "The effectiveness of a "modularization" is dependent upon the criteria used in dividing the system into modules" $[15, \mathrm{p}$. 1053]. The modularization concept is a very generic concept and is used to refer to a diversity of types at various levels and can be either coarse- or fine-grained [e.g. 16]. Fine-grained components are small-sized capturing source-code, whereas coarse-grained components are large components which can encapsulate complete business functions and can be constructed of a number of systems [16]. The concept of modularization can be applied to the software level [15] as well as too the organizational level [10].

When the design of an organization is modularized the elements of the complete design are split up and allocated to different modules. Some parts of the modules can be hidden, whereas other parts need to be visible [15]. The 'hidden' parts should include the design variables that do not affect decisions in other modules and any changes can be confined to that 
particular module. These design variable might be subject to changes, as they can be altered without affecting the interactions with other parts. Other parts need to be visible to enable interaction with other. Any change of these visible parts might affect the interactions with other modules. Design rules need to be obeyed if the modules are to work together [17]. In general, modularization serves three purposes, any of which may justify expenditures to increase modularity [e.g. 17, 18, 19].

- Modularity makes complexity manageable

- Modularity enables parallel work and improvement

- Modularity is tolerant of uncertainty

The manageability is improved by reusing software in other processes. Once designed the management attention can focus on the integration of these modular components. The reuse concept can appear in two distinct ways. On the one hand components can be developed to support a particular business process and can be reused to support many other business processes. On the other hand legacy systems can be viewed as components and the functionality and data in such a system can be reused. By looking at existing systems as components investments in legacy systems can be leveraged [19]. Based on the benefits of modularization, we expect that in our case study the SOE will result in better manageability of the organization.

The software engineering literature has already a history in developing components [15, 20]. Parnas [15] proposed criteria for decomposing system into modules and recommends that systems should be decomposed along lines encapsulating design decisions. Design decisions that are likely result into changes need to be hidden. Parnas argued that decomposition of a system into modules based on a flowchart will block adaptability to changing circumstances. Therefore, we expect in our case study that the service concept will be used to hide design decisions and interfaces among organizational entities will be more standardized and less subject to changes.

Parnas looked at fine-grained software modules. Levi and Arsanjani [20] proposed a systematic method where a goal-oriented model of a business is created and than mapped to a component-based software architecture. They use 'business uses cases' to guide the decompositions of the business domain. This research suggests that the modularization should take the organizational strategy and main business use cases as a starting point.

\section{Research methodology}

The objective of this research is to better understand and analyze the SOE in practice. This analysis can be used by other organizations, who are considering transforming in or are transforming into a SOE. Exploratory research was chosen due to the scarcity of empirical work about the SOE, the need to investigate the nature in detail and because our goal is to analyze the concept for the purpose of theory building.

This research was based primarily on semistructured interviews with organizational representatives and external consultants involved in the creation of the SOE. Documents relating to the history, the set up and operation of the SOE were gathered and examined in order to acquire a good understanding of the operational, technical, management and organizational aspects as well as issues and problems faced during the operation of the SOE.

\section{Case: The Service-Oriented Enterprise}

The company under study is one of the largest financial service providers in the Netherlands consisting of more than twenty brands in multiple markets. Although the Netherlands is their main market, the company is active in many European countries. The company is formed by several acquisitions and mergers in the past. There are several offices geographically scattered around the Netherlands.

Core values of the company are integrity, respect, involvement, professionalism and result-orientation. These core-values are part of the ambition to grow in selling insurance policies on the Dutch market. Besides growing on the current markets, conquering new markets is also one of the strategic objectives. In total 22 thousand employees are working at this company. The IT-division is a kind of staff division and is responsible for the infrastructure which can be used as generic facility by the other organizational parts. After the many acquisitions the company decided that they want to get rid of the orientation on labels and to create service centers that can support several, and if possible, all labels. Moreover, the complete organization is based on a division into service centers, each of which provides a large number of business services which can be used by other business units. New product offerings can be created by making use of the services offered by various service centers.

We took the company as an example of a SOE, as the organization is organized around service centers and in this way service-orientation is applied to the organizational level. In essence, the service centers 
communicate and need to interact with each other to provide a product or service to their customers. Each service center has a number of functions and operations that need to be combined with the function of the other service centers to fulfill a customer need.

The service centers and service orientation is already in place for a couple of years and as such the start-up problems were already overcome and the interviewees were already used to the new type of organization structure.

\subsection{Basic architecture}

The SOE was driven by several mergers and acquisitions, which resulted in a large duplication of activities and the need to restructure the company. The new architecture can be described by making use of a layered model having the customers at the top of the model. Figure 1 shows the layered model. Customers can interact with the business using a number of channels, including offices, call center and several websites. After receiving a customer request the request is routed to the appropriate business domain operated by a service center. In fact each business domain has a pre-defined set of services that can be invoked and used.

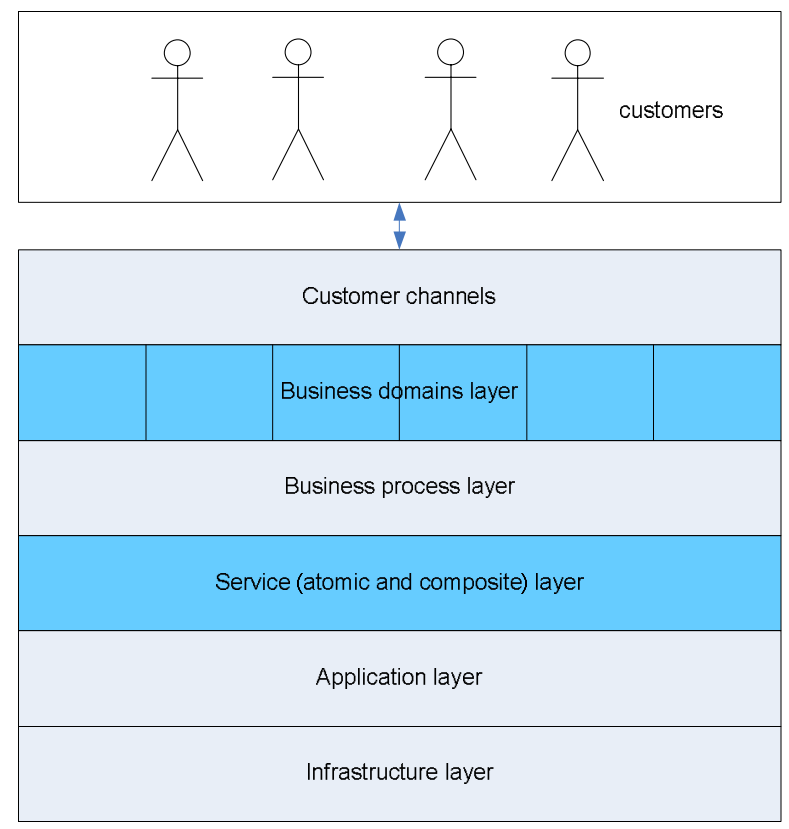

Figure 1. The layered architecture model

In each of the business domains a number of business processes execute the client initiated processes. The business processes rely on the web services in the layer below. A new business process can be assembled by reusing the services that are found in the service layer. The service layer contains web services that can either be atomic or composite. A composite web service is in turn constructed using a number of other services, which can be atomic or composite. The advantage of having atomic and composite services is that this enables the reuse of low granular and high granular services. Composite services are high granular services that have already proven to be working.

The service layer contains a service directory and interfaces that can be invoked. One of the advantages is that in this way the business domains (service centers) are separated, but at the same time each business domain can reuse the services in the service layer. In this way business domains remain autonomous and have their own decision-making structure, whereas at the same time they can reuse services.

The services are implemented in the application layer. There might be various implementations of one service. This enables the migration from an old application to a new application, as both the old and new applications can be invoked. Finally at the bottom the infrastructure layer is shown, which contain the communication bus infrastructure and accompanying basic services like secure transmission.

\subsection{Integrating the components}

The layered architecture is used as a starting point for designing the interactions, business processes, web services and applications. Figure 2 depicts an example of interactions among services in the web site (which is named 'my insurance'. This is a kind of digital safe that customers can use to store and retrieve their data, and follow the status of their requests), the business processes and services used to invoke external applications. The depicted business process is a process that is completely executed within one service center, the service center claims.

If something happened, an insurant can submit a claim. In this example the claim is submitted using the website of the company. The website offers personalized access to all insurance data. The website is used to invoke one of the services of service center claims. After invoking this service, a business process is started. First, the claim is registered, thereafter the information is checked. For this purpose a number of web services are invoked. In a CRM system, operated by the customer data service center, all the customer and policy data is stored. Using a number of web service invocations this information is acquired and used to check the information submitted. After having checked if the insurant is covered by the policy, the 
claim will be checked. This can be done by asking experts to investigate the claim. For small claims, often no check is done. For most claims it is checked whether they are likely to be true and, if they are, the next process step is started. The claim will be validated only after money is paid o the insurant.
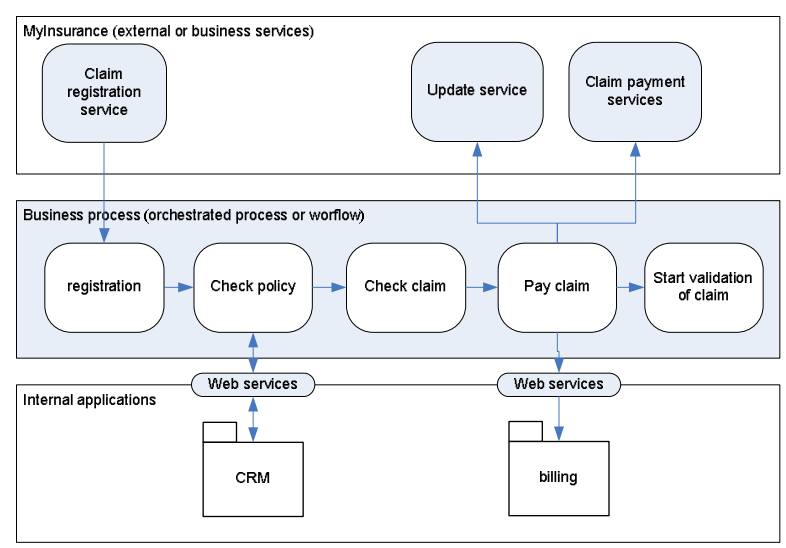

Figure 2. Example depicting the relations among elements within one domain

If the claim service center decides to pay a web service offered by the billing and payment service center is invoked. The billing and payment service center ensures that the claim is paid. In parallel the information in the digital safe of the insurant is updated. After payment a whole procedure for validation can start.

This example shows that a number of service centers are involved in processing the claim. Although the service center claim has the lead in processing the insurant's request, it makes use of the web services (in the service layer) offered by the customer data service center and billing and payment service center. Each service center has its own specialization. The whole process of organization decomposition and integration is realized through the use of service centers aimed at integrating the efforts of the single business services. The service center claim concentrates on performing business process management and orchestration of activities. This service center acts both as a service provider and requester; as a service provider by offering all kind of services related to claims and as a service requester by making use of services offered by other service centers.

Service providers and service requesters make agreements concerning the performance and other requirements as service availability, helpdesk support and so on. Long term agreements concerning the service levels, costs and development of new products and services are needed. Often this is negotiated only once or twice a year. These negotiations results in
SLAs that need to be monitored. SLAs help to strengthen the principal role of service requesters. In case of questions or problems interactions using a help desk of account manager are possible. The helpdesk and account managers are aimed at solving operational, day-to-day questions. Each service centers offers a number of web services that can be invoked by the service. In addition, a number of web services are offered to provide control and monitoring information. In this way the service requester can gain an overview of the performance.

As not every single end-user can make arrangements with a service provider, there is a service center that is aimed at creating new products and ensuring that the existing products are improved by making use of other service centers. This service center is primarily acting on behalf of customers or potential customers. This center makes agreements with service providers about their service offerings, the annual improvements that need to be made and about the development of new services in order to be able to offer new products.

In this way the complete company is organized around service providing and requesting units, named service centers. There are 12 main service centers and service centers act both as service provider and requester. The interactions are not only at a technical level, but also at an organizational level to ensure improvements and make service level agreements.

\section{Discussion}

\subsection{Modularization}

One of the most important phases of the transformation process was the identification of components and accompanying business services. Based on the discussion in the background section, it was expected that the main principle for modulation would be used to hide design decisions. Changing circumstances would result in a change of the 'hidden' parts of a module and not in the visible parts affecting possibly affecting other modules.

In our case study we found both low granular and high granular services. Fine-grained services are smallsized often encapsulating one information system, whereas coarse-grained components are large encapsulating complete business functions and often multiple systems. The low granular services have a complete other dynamics than high granularity. We tried to analyze the history of determining the type of service centers using documents and interviews. We found that it was hard to trace them back to the origins, as it was a highly intuitive and interactive process. The 
use of power to influence decision-making and the already existing organization were said to have a large influence on the outcomes.

The whole modularization process initially remained at a very high level of abstraction. First the main service centers were determined by an interactive process which primarily involved high-level managers. Only after these decisions were made the details and interactions were considered. Although the interviewees indicated that some problems were encountered that might be solved by changing boundaries, it was decided not to change the initial organizations of the business centers. Thus the specification of already existing components and departments that might act as service centres was taken into account. The design method was based on successive refinements of the system requirements until a suitable concrete implementation of the final application's components was reached. There are many different ways to cluster shared services. Within insurance companies there are at least four important views that are used to divide the enterprise into components. Modularization was based on type of products, functionality, expertise and information systems.

1. Products, e.g. service center life insurance, health insurance, care insurance.

2. Functionality, e.g. service Center collecting payment or paying claims

3. Expertise needed, e.g. service center law

4. Information Systems, e.g. service center infrastructure, project management.

The criteria are not mutually exclusive and the clustering using different criteria can result in the same outcomes. For example project management can be viewed as supporting the development of a type of information system, but also as a type of expertise. So it can be derived using two types of clustering techniques. The functionality view has an implicit process views, as functionality is used to support the complete life-cycle of insurances.

We used the guidelines of Parnas [15] to evaluate the componentization of the company under study. In general, we found that the componentization of the enterprise followed the guidelines proposed by Parnas, although implicitly.

1. Minimize the interactions with the environment and standardize the services interfaces;

2. Create a well-defined interface and make a set of service levels agreements;

3. Every component contains a logical cluster of business objects and information needs that can be used to operate a business process autonomously;
4. There should be clear interfaces describing the inputs, outputs and responsibilities to ensure accountability;

5. Establish governance mechanisms to integrate the components not only at the technical level, but also at the organizational level.

In our case study the service centers are derived using an interactive process. Investigation of this process shows that one of the most important guidelines that was followed in the change process was that organizational changes should be minimized. If a 'current' department had already the shape of a possible module in the SOE, it will become one. Only small, incremental steps were taken and in this way the modules evolved over time. Taking these small steps already proved to be difficult.

The service centers are geographically dispersed and even one service center might be at several geographical locations. As such governance mechanisms dealing with the dynamics and ensuring the integration at an organizational level and making sure that persons communicate with each other were found to be crucial.

A major research challenge is defining a methodology for modularization of the business. Existing modularization approaches often assume a stable business environment in which it is possible to determine design decisions and other elements subject to change and anticipate any other future changes. In reality, the environment is not static and business goals are agreed on by heterogeneous types of stakeholders. Our case study suggest that organizational boundaries are dependent of the interdependencies between tasks that make up a business processes. Moreover, modularization should look at existing software systems within an organization or components readily available from software vendors. Furthermore, modularization should take into account the current organization arrangement and capitalize stakeholders' knowledge and experience.

\subsection{Interoperability}

Interoperability requires that it is necessary to create a coherent information systems architecture in which the various systems can be integrated. The necessity to develop interoperable systems is hindered by the very nature of the existing enterprise information systems, including legacy systems, which are often proprietary having heterogeneous data structures and technologies.

An information architecture was created as the basis for the interoperability. Nevertheless the interviewees indicated that the creation of a new 
business processes by reusing the services took often more than half a year. Although SOA using web services helped to make them interoperable from a technological point of view, problems remained at the semantic and pragmatic level. The main hurdles were not concerned with connecting systems, as one interviewee stated 'we can create a new interface within a minute'. Instead the main problems are concerned with negotiating the divisions of costs, service level agreements, changing and updating the information systems and preparing and making the staff ready for the change. Often for a new product a separate department was created within a service center. This department becomes responsible for processing the product and makes use of the available systems and expertise. The major issue did not concern the adaptation of the information systems, but the change of the organization. The information architecture helped to some respect, but is not sufficient for creating interoperability.

\subsection{Evolution}

In the granularity subsection we already discussed that the SOE rather emerged and was negotiated than based on a pre-designed blueprint developed in a rational design process. The company was a result of various mergers and acquisitions. Consequently there ware a large number of departments who were doing similar things for different labels (brands). The board wanted to avoid this large duplication of efforts and to concentrate specialists in one department. For example, there were a number of departments who processed claims for different types of insurances and for different labels. The idea of the SOE is that first modules were identified and then all similar activities would be merged into one service center. In our example this service center should provide a standardized pallet of services to process claims. This would reduce diversity, avoid duplication of efforts and ultimately result in lower costs. Moreover, by concentrating them together this would result in economies of scale and scope.

The focus of the implementation projects of the SOE are on designing a set of modules and accompanying services that enable the flexible creation of business processes for providing new products. This required the retooling of the enterprise and the creation of supporting environments for different business contexts. The architecture of the company has actually emerged as a result of implementing individual projects. It is this de facto architecture, not the conceptual one that was made on the drawing board, that makes up the SOE. Therefore understanding the organizational capabilities for executing business strategies, and understanding this emergent architecture is of paramount importance. Dynamic capabilities are aimed at helping a firm to adjust its resources [21]. Teece et al. [21] have suggested a 'dynamic capabilities' view, also called dynamic resources. Teece et al. define dynamic capabilities as "the firm's ability to integrate, build, and reconfigure internal and external competences to address rapidly changing environments“ $[21$, p. 516]. They argue that sustainability lies with a firm's managerial and organizational processes, which are shaped by the firm's asset position and the paths available to it. The results of our case suggests that the design of a SOE should take this dynamic capabilities view into account, as the modularization was dependent on the history and subject to political struggle.

The interviewees indicated that several times there was a tendency to bypass, especially bad performing, service centers when creating a new product. Instead of reusing the services, several times investments were budgeted to build a new service. If possible, the bypassing was blocked, however, it is hard to convince people of making use of a badly performing service center. As main challenges remain the management of reuse and the avoidance of the development of too many services and service centers.

\subsection{Benefits and disadvantages}

In this case study the basic idea the SOE is that each service center is specialized in performing certain tasks and functions and can benefit from specialization. Each service center specializes in performing certain types of roles and activities and should be able to benefit from economies of scope and scale. We observed a number of benefits and disadvantages in different fields. The four categories and motives for outsourcing decisions suggested by Baldwin, Irani and Love [22] are taken to categorize the benefits and disadvantages. During the interviews the implicit benefits and disadvantages for establishing a services and service centers have been discussed and after each interview the list was updated.

\section{Strategic and organizational benefits}

- Each of the service centers can focus on its core business and can act autonomously. This contributes to a clear governance structure;

- Clear relationships by using SLAs, however, improvement and innovation are not well supported by the SLAs. Conversely, improvements and innovations often need an 
organizational-wide approach, whereas the SOE emphasizes the individual service centers;

- Gain access to high quality IT services and skills by concentration of expertise in a service center. In the past this expertise was scattered over a large number of organizational units;

- For each type of service there is a clear service provider acting as a one-stop shop and providing all support concerning the use, customization and adaptation of the service. The drawback is that for every product a new service is created that needs to be maintained;

- Functionality and business processes within service centers are standardized per product. For different products there are some differences, however, they are kept to a minimum. This enables the rotating of employees among different products within a service center.

- The aim for more standardized service provisioning and accomplishing higher costsavings has a negative impact on customized service provisioning;

- Reduction of complexity by having clearly defined service centers who take care of the execution. Only the need for which services and the accompanying service levels need to be managed;

- The time-to-market has improved substantially in comparison with the preceding situation. Although the interviewees indicate that the time-to-market is still half a year, which is longer that the initial objectives.

The interviewees indicated that the SOE helped them to focus on their core business and makes control more clear, as there is a service provider and a requester. The standardization of the services would also result in clarity and the provider-requester relationship would result in a better customer focus. Still the interviewees indicated that listening to the service requesters was often badly done.

One of the main benefits that were mentioned was the reduced time-to-market. As new product development departments could concentrate on making new products and make use of services offered by service centers they find the complexity of new product offerings less.

\section{Political benefits}

- Internal conflicts are solved by concentrating similar functions in one service center. On the other hand, new conflicts emerge within a service centers, e.g. which information system should we use, which department and employees do what. Furthermore, two types of new conflicts were mentioned. Firstly, badly performing services center are sometimes bypassed by other centers when creating a new product. Secondly, if something goes wrong, service centers are blaming each other;

- Increase controllability of operational costs. The income of the service centers is based on the services provided and not based on fixed budget. Each year the payment is negotiated and actual payment is based on the number of services provided and the performance attained in comparison with the service levels that were agreed on. As a result the income might be subject to fluctuations and it can happen that the revenues are sometimes to low to pay for the expenses in a given period of time.

The political benefits are particularly coming from the solving of internal conflicts, which emerged from the many mergers and acquisitions. Organization around service centers results in less conflicts as all similar activities are concentrated in a service center. Moreover, a benefit would be the increase of the controllability of the costs.

\section{Technical benefits}

- Concentration of technical and project management expertise for the various products result in better access to domain specific expertise;

- A service center can be viewed as an expertise center for its activities. It concentrates all the knowledge and experiences in the field.

- Staff can easier be re-allocated from one product to another product and consequently the utilization of the staff is improved. Which resulted in higher services levels;

- $\quad$ Escape from legacy systems. By concentrating all related functions in a service center, the number of systems could be reduced. Some systems became superfluous and the 'best' system could be kept. In turn this caused conflicts as some of the departments preferred their own system over the selected system.

- Standardization of platforms and application vendors. In this way the type of IT-expertise needed could be reduced and the number of different systems that need to be controlled and maintained was reduced.

- Better information security and authorization by centralizing all security efforts in one service center. This service center provides its knowledge, know-how and single sign-on service to the other service centers. 
A major advantage from the technical point of view is that each service center acts as a center of expertise. A service center can be viewed as a means to obtain and develop expertise. Due to the mergers and acquisitions a hodgepodge landscape of systems was created having a duplication of task and activities, using other data models and other hardware. Once a new service center was founded several of the old legacy systems could be abandoned and replaced by one of the other systems. This helps to accomplish profits from the mergers and acquisitions and create a reliable set of information systems. Moreover, as there are less systems in total, less control and maintenance is necessary resulting in lower costs and the freeing of scarce human resources. These human resources can be used to develop and improve other systems. This is of special importance as there was a shortage of skilled staff.

\section{Economical benefits}

- Lower control and maintenance costs as less information systems need to be controlled and maintained;

- Accountability of control. Clearer governance based on SLAs results in easier allocation of budgets and accountability. On the other hand, this result in a focus on service provisioning and less attention is given to improvement and innovations;

- Each service center specializes in certain tasks and functions resulting in economies of scope and scale. The potential savings are limited as for most products the services are customized.

The interviewees were not all convinced of large cost saving as an economical benefit. According to some interviewees the financial reports can be used to shows that the operational costs were lowered, whereas others were saying the extra activities like making of SLAs become necessary which have added costs. Moreover, some cost savings are coming from the removal of legacy systems and standardization and the interviewees questioned if this was caused by serviceorientation. These benefits could have been accomplished in other ways. Our finding are conform the findings in outsourcing literature [23]. Hirschheim and Lacity found that "there is no guarantee it will be perceived as successful due to the very different expectations held by the various stakeholders. Success is related to who is doing the evaluating" [23, p. 107].

\section{Conclusions}

In this paper we explored the service-oriented enterprise in practice by conducting a case study. In our case study the SOE was created by modularization of the organization in service requesters and providers. Next, the modules are integrated by negotiations between the requester and providers, the making of service level agreements and the invocation and execution of the services.

In our case study, we found that there are a variety of low and high granular services and different types of services that have evolved over time. Identifying the modular services is difficult and requires long-lasting negotiation processes. The SOE of the company evolved and emerged over time. The organization was modularized using an interactive process and modularization is based on type of products, functionality, expertise and information systems. The five guidelines for software modularization proposed by Parnas [15] proved to be sensible for the SOE, however the outcomes of the modularization process seem to be more determined by path-dependent histories and political struggle rather than by a rational decision-making process based on these guidelines. The business environment is dynamic and therefore there is a need for continuous change. A new important guideline was found; if possible organizational change should be kept to minimum.

Although a single case study methodology cannot claim to offer prescriptive solutions of guidelines and best practices, it does link theory and practice and allows us to raise a number of points and make a number of suggestions. A SOE is might provide other benefits and disadvantages than initially expected. The main promise was cost reduction and easier governance of the enterprise. Our findings indicate that in our case study the service-oriented enterprise has advantages concerning the time-to-market, reduction of complexity, reduction of duplicate systems and clarity of governance. We found no support for the SOE actually making governance easier, as new types of problems appear.

In this paper we investigated only one type of the SOE and it is very likely that other types of SOE are possible. We plea for conducting more case studies in this area to analyze a diversity of SOEs. In these types of research the evolution path towards becoming a SOE and the dynamic capabilities of the organization to create the SOE should be analyzed. Moreover, there is a need for comparative case studies to investigate various types of SOE, the type of modules derived, modularization guidelines and their related benefits 
and disadvantages. Ultimately, this should result in a theory for the service-oriented enterprise.

\section{References}

[1] P. Fremantle, S. Weerawarana, and R. Khalaf, "Enterprise services. Examine the emerging files of web services and how it is integrated into existing enterprise infrastructures," Communications of the ACM, vol. 45, pp. 77-82, 2002.

[2] Y. Rezgui, "Role-based service-oriented implementation of a virtual enterprise: A case study in the construction sector," Computers in Industry, , vol. 58, pp. 75-86, 2007.

[3] B. Gold-Bernstein and W. Ruh, Enterprise Integration. The essential guide to integration solutions: Addison-Wesley, 2005.

[4] H. Demirkan, M. Goul, and G. W. Brown, "Towards the "Service-oriented Enterprise"," presented at 40th Annual International Conference on Systems Sciences (HICSS40), Big Island, Hawaii, 2007.

[5] L. Cherbakov, G. Galambos, R. Harishankar, S. Kalyana, and G. Rackman, "Impact of service orientation at the business level," IBM Systems Journal, vol. 44, pp. 653-668, 2005.

[6] M. P. Papazoglou and D. Georgakopoulos, "Service-oriented Computing: An introduction," Communications of the ACM, vol. 46, pp. 24-28, 2003.

[7] M. Janssen, J. Gortmaker, and R. W. Wagenaar, "Web service orchestration in public administration: Challenges, roles and growth stages," Information Systems Management, vol. 23, pp. 44-55, 2006.

[8] Automatseringsgids, "Een op drie financiële instellingen al bezig met SOA," in Automatiseringsgids, 2007, pp. 6.

[9] B. Bergeron, Essentials of Shared Services: John Wiley \& Sons, 2003.

[10] M. Janssen and A. Joha, "Motives for Establishing Shared Service Centers in Public Administrations," International Journal of Information Management, vol. 26, pp. 102-116, 2006.

[11] J. Yang, "Web service componentization," Communication of the ACM, vol. 16, pp. 35-40, 2003.

[12] F. Curbera, "Unraveling the web services web: An introduction to SAP, WSDL, UDDI," IEEE Internet Computing, vol. 6, pp. 86-93, 2002.

[13] J. R. Galbraith, Organization Design. Reading, Massachusetts: Addison-Wesley, 1977.
[14] D. E. Cox and H. Kreger, "Management of the service-oriented life-cycle," IBM Systems Journal, vol. 44, pp. 709-726, 2005.

[15] D. L. Parnas, "On the criteria to be used in decomposing systems into modules," Communications of the ACM, vol. 15, pp. 10531058, 1972.

[16] A. Arsanjani, "Developing and integrating enterprise components and services," Communications of the ACM, vol. 45, pp. 31-34, 2002.

[17] C. Baldwin and K. B. Clark, Design Rules, Volume 1, The Power of Modularity. Cambridge, MA: MIT Press, 2000.

[18] D. L. Parnas, P. C. Clements, and D. M. Weiss, "The modular structure of complex systems," presented at Proceedings of the 7th international conference on Software engineering Orlando, Florida, USA, 1984.

[19] M. Janssen and R. W. Wagenaar, "From Legacy to Modularity. A roadmap towards modular architectures using web services technology in egovernment," presented at Second International Conference, EGOV 2003, Prague, 2003.

[20] K. Levi and A. Arsanjani, "A goal-driven approach to enterprise component identification and specification," Communications of the ACM, vol. 45, pp. 45-52, 2002.

[21] D. Teece, G. Pisano, and A. Shuen, "Dynamic capabilities and strategic management," Strategic Management Journal, vol. 18, pp. 509-533, 1997.

[22] L. P. Baldwin, Z. Irani, and P. E. D. Love, "Outsourcing Information Systems: drawing lessons from a banking case study," European Journal of Information Systems, vol. 10, pp. 1524, 2001.

[23] R. Hirschheim and M. Lacity, "The myths and realities of information technology insourcing," Communications of the ACM, vol. 43, pp. 99$107,2000$. 